Chapter 15

\title{
New Therapeutic Approaches to Conventional Surgery for Aortic Stenosis in High-Risk Patients
}

\author{
Omer Leal, Juan Bustamante, Sergio Cánovas and \\ Ángel G. Pinto
}

Additional information is available at the end of the chapter

http://dx.doi.org/10.5772/54333

\section{Introduction}

Aortic stenosis (AS) is the most frequent type of valvular heart disease in Europe and North America. It mainly presents as calcified aortic stenosis in older adults (2-7\% of the population> 65 years), which is the most common cause of valve replacement in the western world. Its incidence increases with age [1]. With the increasing age and life expectancy of the population, an increase in the prevalence of aortic stenosis had been observed. Furthermore, the elderly patient usually presents multiple comorbidities associated with increased surgical risk. Aortic valve replacement (AVR) is currently the treatment of choice in patients with symptomatic aortic stenosis and/or left ventricular systolic dysfunction (see Indications for surgery), even though some cases present high or extremely high surgical risk.

Our goal is to update the treatment of severe aortic stenosis in high-risk patients, mainly the elderly and those cases where risk assessment scales indicate a high- or very high-risk patient. Here we analyse the role of new therapeutic approaches in the treatment of these patients and their short and long-term results, as well as the use of new devices and prosthesis.

\section{Etiology}

AS without accompanying mitral valve disease is more common in men than in women [2] and rheumatic etiology is currently rare. Age-related degenerative calcific AS is currently the most common cause of AS in adults and the most frequent reason for aortic valve replacement (AVR) in patients with AS. Sclerosis of the aortic valve is observed in up to $30 \%$ 
of elderly people: $25 \%$ of people aged 65 to 74 , and $48 \%$ of people older than 84 years $[3,4]$. This calcific disease progresses from the base of the cusps to the leaflets, eventually causing a reduction in leaflet motion and effective valve area without commissural fusion. Calcific AS is an active disease process characterized by lipid accumulation, inflammation, and calcification, with many similarities to atherosclerosis. In approximately half of cases there is a bicuspid aortic valve basis. Bicuspid aortic valve valvulopathy affects $2 \%$ of the population, making it the most frequent congenital anomaly, representing the more common cause among young adults [5].

\section{Evaluation and grading the degree of stenosis}

Patient history and physical examination remain essential. Careful exploration for the presence of symptoms (shortness of breath on exertion, angina, dizziness, or syncope) is critical for proper patient management. It is important to be aware that patients may not notice symptoms but they significantly reduce their activities. The characteristic systolic murmur draws attention and guides further diagnostic work in the right direction. However, on occasion the murmur may, be faint and the primary presentation may be heart failure of unknown cause. The disappearance of the second aortic sound is specific to severe AS, however, it is not a sensitive sign.

Several studies [6-9] reports that biomarkers such as B-type natriuretic peptide (BNP) has been shown to be related to functional class and prognosis, particularly in AS and MR. In fact, Lancellotti et al. [9] reports in their study that a left atrial area index of $>$ or $=12.4$ $\mathrm{cm} 2 / \mathrm{m} 2$, systolic annular velocity of $<$ or $=4.5 \mathrm{~cm} / \mathrm{s}$, E/Ea ratio $>13.8$, late diastolic annular velocity of $<$ or $=9 \mathrm{~cm} / \mathrm{s}$, and BNP of $>$ or $=61 \mathrm{pg} / \mathrm{ml}$ were identified as the best cutoff values to predict events (death, symptoms, or surgery). They found, in asymptomatic AS, tissue Doppler imaging and BNP measurements provide prognostic information beyond that from clinical and conventional echocardiographic parameters. However, Natriuretic peptides have been shown to predict symptom free survival and outcome in normal- and low-flow severe AS and may be useful in asymptomatic patients, helping to discriminates those patients who can benefits from an early intervention [7-9]. Nevertheless, evidence regarding its incremental value in risk stratification remains limited so far.

Echocardiography is indicated when there is a systolic murmur of grade III/VI or higher, a single S2, or symptoms that might be due to AS [10]. A 2-dimensional (2D) echocardiogram is valuable for assessing valve anatomy and function and determining the LV response to pressure overload. In nearly all patients, the severity of the stenotic lesion can be defined with Doppler echocardiographic measurements. Echocardiography is also used to assess LV size and function, degree of hypertrophy, and presence of other associated valvular disease. Transoesophageal echocardiography (TOE) is rarely helpful for the quantification of AS, as valve area planimetry becomes difficult in calcified valves [11] however, it is useful when transthoracic visualization is poor and leaflets only moderately calcified [12]. TOE may, however, provide additional evaluation of mitral valve abnormalities and has gained impor- 
tance in assessing annulus diameter before TAVI and in guiding the procedure. Intraprocedural TOE enables us to monitor the results of percutaneous procedures [11]. Threedimensional TOE offers a more detailed examination of valve anatomy than twodimensional echocardiography and is useful for the assessment of complex valve problems or for monitoring surgery and percutaneous intervention [11]. Three-dimensional echocardiography (3DE) is useful for assessing anatomical features which may have an impact on the type of intervention chosen, if it is needed. AS severity could be graded on the basis of a variety of hemodynamic and natural history data, using definitions of aortic jet velocity, mean pressure gradient, valve area and velocity ratio as shown in Table 1.

\begin{tabular}{llll}
\hline & \multicolumn{2}{c}{ Aortic Stenosis } \\
\hline Indicator & Mild & Moderate & Severe \\
\hline Aortic jet velocity $(\mathrm{m} / \mathrm{s})$ & $2.6-3$ & $3-4$ & $\geq 4$ \\
\hline Mean gradient $(\mathrm{mmHg})$ & $\leq 30(25)$ & $30-50(25-40)$ & $\geq 50(40)$ \\
\hline Indexed AVA $\left(\mathrm{cm}^{2} / \mathrm{m}^{2}\right)$ & $\geq 0.9$ & $0.6-0.9$ & $\leq 0.6$ \\
\hline AVA $\left(\mathrm{cm}^{2}\right)$ & $\geq 1.5$ & $1-1.5$ & $\leq 1$ \\
\hline Velocity ratio & $\geq 0.50$ & $0.25-0.50$ & $\leq 0.25$ \\
\hline
\end{tabular}

Table 1. Classification of the Severity of Aortic Valve Disease in Adults

Based on the European Society of Cardiology (ESC) Guidelines on the management of valvular heart disease [12], American College of Cardiology/American Heart Association (ACC/ AHA) Guidelines for the Management of Patients With valvular heart disease [10] and ASE/EAE Recommendations for Quantitation of Stenosis Severity, [13] ACC/AHA guidelines use lower mean gradient cutoffs as indicated in parentheses. The ESC definitions apply only in the presence of normal flow conditions. The velocity ratio is included in the ASE/EAE guidelines only.

Multi-slice computed tomography (MSCT) and cardiac magnetic resonance (CMR) provide additional information on the assessment of the ascending aorta when it is enlarged. MSCT may be useful in quantifying the valve area and coronary calcification, which aids in assessing prognosis. MSCT may contribute to the evaluation of the severity of valve disease, particularly in AS, either indirectly by quantifying valvular calcification, or directly through the measurement of valve planimetry. Also, MSCT has become an important diagnostic tool for evaluation of the aortic root, the distribution of calcium, the number of leaflets, the ascending aorta, and peripheral artery pathology and dimensions before undertaking TAVI [11]. In patients with inadequate echocardiographic quality or discrepant results, CMR should be used to assess the severity of valvular lesions - particularly regurgitant lesions - and to assess ventricular volumes and systolic function, as CMR assesses these parameters with higher reproducibility than echocardiography [11]. In practice, the routine use of CMR is limited because of its limited availability, compared with echocardiography. Due to its high negative predictive value, MSCT may be useful in excluding CAD in patients who are at low risk 
of atherosclerosis [11]. MSCT plays an important role in the work-up of high-risk patients with AS considered for TAVI. The risk of radiation exposure-and of renal failure due to contrast injection-should, however, be taken into consideration.

There are contraindications for exercise testing in symptomatic patients with AS, however it is useful for unmasking symptoms and in the risk stratification of asymptomatic patients with severe AS [12]. Stress tests are currently under-used in patients with asymptomatic AS. In some patients, it may be necessary to proceed with cardiac catheterisation and coronary angiography at the time of initial evaluation [10]. This could be appropriate if there is a discrepancy between clinical and echocardiographic examinations or if symptoms might be due to coronary artery disease (CAD).

\section{Indications for surgery}

Early valve replacement should be strongly recommended in all symptomatic patients with severe AS, because it is the only effective treatment. Thus, the development of symptoms identifies a critical point in the natural history of AS. The interval from the onset of symptoms to the time of death is approximately 2 years in patients with heart failure, 3 years in those with syncope, and 5 years in those with angina, with a high risk of sudden death (Figure 1).

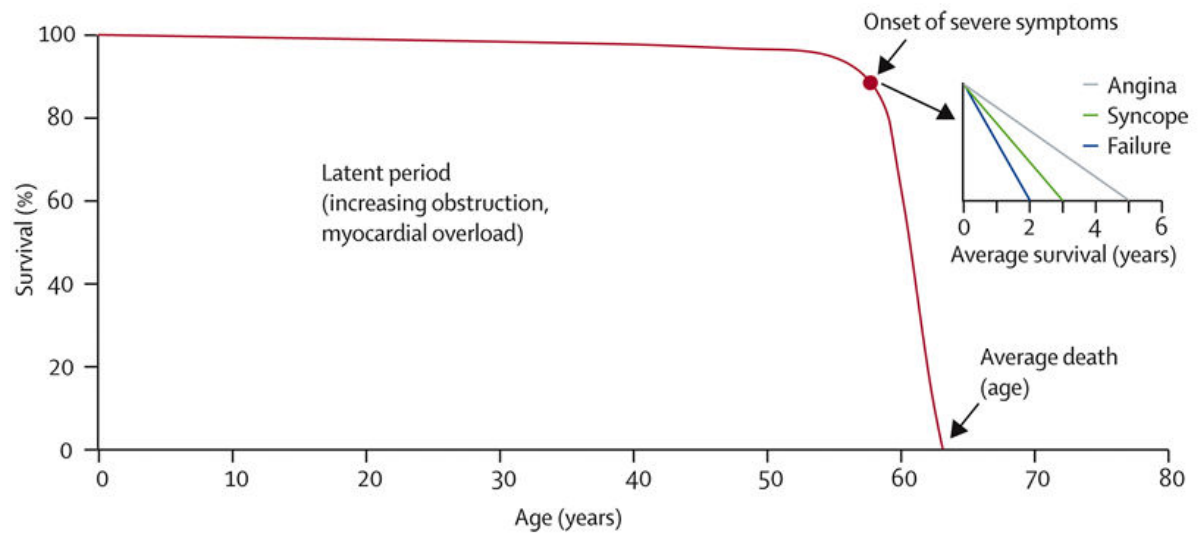

Figure 1. Natural History. Ross J Jr. \& Braunwald E, 1968 [14]

There is some disagreement about the optimal timing of surgery in asymptomatic patients, and the decision to operate on this kind of patient requires careful weighing of the benefits against the risks. Early elective surgery, at the asymptomatic stage, can only be recommended in selected patients, with low operative risk [12]. A proposed management strategy for 
patients with severe AS based on the ESC Guidelines on the management of valvular heart disease [12] and ACC/ AHA Guidelines for the Management of Patients with valvular heart disease [10] is shown in Figure 2.

Although there are no prospective randomized trials, data from retrospective analysis indicates that patients with moderate AS (mean gradient in the presence of normal flow 30-50 $\mathrm{mmHg}$, valve area $1.0-1.5 \mathrm{~cm}^{2}$ ) will generally benefit from valve replacement at the time of coronary surgery. However, individual judgement must be recommended [12], based on the evolution of the echocardiography severity parameters and the patient's clinical evaluation.

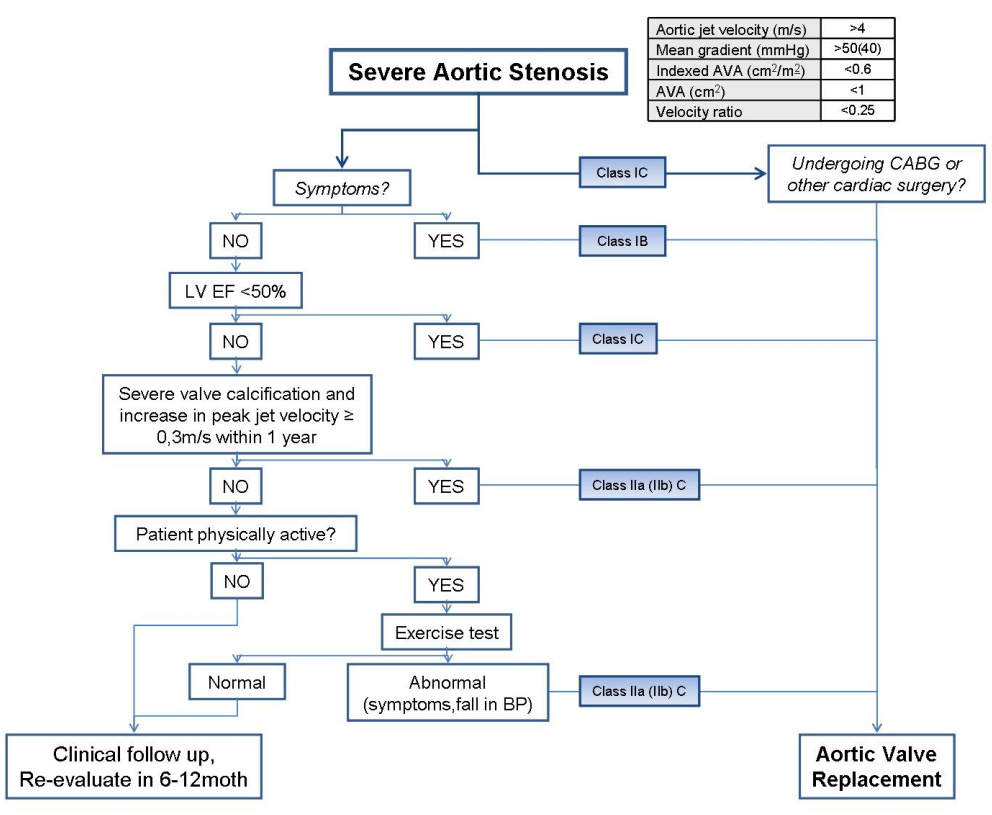

Figure 2. Management of Severe Aortic Stenosis.

Based on the ESC Guidelines on the management of valvular heart disease [12] and ACC/ AHA Guidelines for the Management of Patients with valvular heart diseaseb [10]. ACC/AHA recommendations has been shown in parentheses.

\section{Risk stratification}

Patient selection for AVR for AS is well outlined by ACCF/AHA and ESC guidelines. Problems arise when the patients present significant symptoms and significant structural disease, complicated by the presence of significant comorbidity. A number of risk algorithms for cardiac surgery have been developed. Experience accrued since the development of the Parson- 
net scale reveals that this scale assigns too much weight to age. Nowadays the STS score and logistic EuroSCORE are the most commonly used. These provide information concerning short term operative risks, however, they are not able to predict symptom resolution, quality-of-life improvement, or return to independent living.

As discussed above (see also Evaluation and Grading the Degree of Stenosis), several studies have reported the usefulness of BNP in risk stratification of asymptomatic or mildly symptomatic patients, which could help to discriminate which patients would benefit from an early surgical management. However, there is not enough evidence to recommend the routine use of these biomarkers.

Although both are accurate in low-risk patients, accuracy is reduced in higher-risk subsets [15]. The logistic EuroSCORE is based on 12 covariates derived from 14,799 patients undergoing all types of cardiac operations in 8 European countries in 1995. On the other hand, the STS risk predictor is based on 24 covariates derived from 67,292 patients undergoing isolated AVR only in the United States between 2002 and 2006. Both use an algorithm based on the presence of coexisting illnesses in order to estimate 30-day operative mortality. There is a much simpler variation of the EuroSCORE logistic model, which can be calculated at the patient's bedside, adding points manually. This model is called the additive EuroSCORE. It assigns a specific value to each risk factor, and the points are simply added to obtain the estimated operative mortality rate.

With improved outcomes after cardiac surgery in more recent years, EuroSCORE has become less well calibrated. EuroSCORE II has been developed using data from 22.381 patients who underwent cardiac surgery during 2010, and represents a necessary and timely update of the original EuroSCORE models. EuroSCORE II improves on the original logistic EuroSCORE, though mainly for combined AVR and CABG cases. However, concerns still exist, about its use for isolated AVR procedures, aortic surgery and miscellaneous procedures. There is still room for improvement in risk modelling and several studies are currently being carried out to validate EuroScore II. Nevertheless, Grant et al [16] report that EuroSCORE II performs well overall in contemporary UK adult cardiac surgery, with good discrimination for all kinds of cardiac surgery; in fact, they report that the logistic EuroSCORE is now obsolete and their study demonstrates that it is appropriate to use EuroSCORE II as a generic risk model for contemporary UK cardiac surgery.

There is growing debate about the definition of high-risk patients and the validity of risk assessment using different risk-scoring systems for prediction of mortality (see also HighRisk Patient). Current models do not include some risk factors that may be particularly important in the prediction of outcomes for high- or very high-risk populations including frailty, pulmonary hypertension $(\mathrm{PH})$, porcelain aorta, and the presence of hepatic dysfunction, although all these have been included in EuroSCORE II.

Nevertheless, the sample of elderly patients considered for the design of these scales represents a small proportion of the population, resulting in less accurate risk assessment, and interpretation should be made with caution. In this regard, a recent study which included 1245 elderly patients (mean age 77.2 years) who underwent AVR with or without CABG re- 
ports that only STS-PROM correlated with mortality rates [17]. Thielmann et al [18] also report that the logistic EuroSCORE and the Parsonnet score clearly overestimated the risk of mortality, whereas the STS score and the additive EuroSCORE were much more accurate in predicting the risk of mortality.

Certain authors, such as Rosenhek [19] and others, suggest the need to include other variables such as cognitive function and functional capacity in surgical risk stratification, mainly in the elderly group. There are physiological characteristics inherent to elderly patients that make them different in risk estimation; an example of this is the amount of creatinine considered in the EuroSCORE scale as a predictor of mortality. This scale assigned a particular score ( 2 points) to patients with creatinine levels greater than $2.26 \mathrm{mg} / \mathrm{dl}$, which through a logistic regression analysis could estimate risk in percentage terms. However creatinine is not the best parameter to define renal function and its value can be influenced by various factors such as age, race, muscle mass and metabolic state, as has been demonstrated in several studies, hence glomerular filtration rate provides a much more accurate estimation [20]. Obviously in the elderly there is a physiological involution of organs and systems that should be taken into account since surgery represents a stressful situation that can reveal or tip the balance for certain pathologies. However, numerous reports have demonstrated excellent results in terms of morbidity and mortality in most patients. Hospital mortality is significantly related to the preoperative presence of depressed left ventricular systolic function, pulmonary hypertension, symptoms of heart failure, kidney failure, long-standing mitral valve disease, and nutritional deficiencies. When these risk factors are absent in the preoperative period, mortality is similar to that of the youngest patients. It should be emphasized that risk models serve as one aspect of patient selection, but need to be considered alongside clinical judgement and other methods of risk assessment.

\section{High risk and elderly patients, are they the same?}

\subsection{Elderly patient}

The ageing of the population is an important social and sanitary phenomenon. Consensus about allowing access to health care unconstrained by age limits, together with increased life expectancy and advances in highly specialised medicine have brought us to the point where surgical treatment is indicated in progressively older sectors of the population [21]. The diagnosis and management of valvular heart disease in the elderly has been affected by the dramatic increase in life expectancy that began in the last half of the 20th century. In the United States, for example, the number of persons aged 80 years or older is expected to increase from 6.9 million in 1990 to approximately 25 million by the year 2050. As a result, degenerative valve disease is likely to become an increasing problem. In the Helsinki Ageing Study [22], 501 randomly selected men and women aged 75 to 86 underwent imaging and Doppler echocardiography. The prevalence of at least moderate aortic stenosis, defined as an aortic valve area (AVA) $\leq 1.2 \mathrm{~cm}^{2}$ and velocity ratio $\leq 0.35$, was 5 percent; the prevalence of critical aortic stenosis (AVA $\leq 0.8 \mathrm{~cm}^{2}$, and velocity ratio $\leq 0.35$ ) increased with age from 1 to 2 
percent in persons aged 75 to 76 up to almost 6 percent in those aged 86 . With the rapidly increasing geriatric population, it is common in current practice to have elderly patients referred for surgical treatment of AS. In 2006, in the United States, approximately $40 \%$ of patients undergoing AVR were at least 75 years old Nevertheless, even though valve replacement is the procedure of choice in this population, currently a large percentage of suitable candidates are, unfortunately, not referred for surgery, mostly because of their age.

As in [21], increased risk in these patients is related to:

- Ageing, which causes structural changes in the heart and reduces the physiological reserves of most organs, thus impairing the capacity to recover from surgical aggression;

- An increase in associated diseases, as studied by Rodríguez et al [23], especially diabetes, kidney failure, arterial hypertension, chronic obstructive pulmonary disease, and cerebrovascular disease;

- The advanced phase of heart disease, as indicated by the greater incidence of heart failure, depressed left ventricular function, and preoperative pulmonary hypertension;

- Reduction of the inflammatory response to surgical aggression,

- Undernourishment, measured by anthropometric and biochemical parameters, which is a frequent preoperative finding before cardiac surgery; its incidence is even greater in older persons and is associated with an increment in postoperative complications due to an impaired response to surgical aggression.

- The increased complexity of surgical techniques for these patients, due to the presence of severe calcification of the aortic ring and the greater incidence of associated coronary and valvular surgery, which require longer aortic clamping times.

Age has been considered an independent predictive factor for mortality, but the way to estimate its influence on the calculation of the risk of surgery has evolved since the introduction of the Parsonnet risk scale, which gave excessive weight to age. Currently the most accepted risk assessment tools are the STS-PROM score and EuroSCORE (with the EuroSCORE II currently being validated).Although they are widely used, there is a possibility of overestimating the operative mortality rates by using these risk-prediction models, and an inescapable discrepancy between the estimated and observed mortality rate has been acknowledged. In a study published in Ann Thorac Surg in 2009 Thielmann et al [18] report that the logistic EuroSCORE clearly overestimates the risk of mortality, whereas the STS score seems to be more accurate in predicting the risk of mortality. Moat et al. [24] also report the relative lack of utility of EuroSCORE in risk/outcome prediction for their group of patients and confirm the need for more sophisticated and procedure-specific (rather than generic) scoring systems. There is no perfect method for weighing all of the relevant factors and identifying specifically high- and low-risk elderly patients, but this risk can be estimated well in individual patients, and the decision to proceed with surgery should depend on many factors, including the patient's wishes and expectations.

Although the proportion of elderly patients with multiple comorbidities is increasing, operative outcomes following AVR have improved over the past decade. Likosky et al [25] pub- 
lished the outcomes of the very elderly undergoing aortic valve surgery in a study comprising 7584 patients, including 815 over the age of 80 . They found that short- and longterm survival was favourable across all age groups. Specifically, more than half of the patients undergoing aortic valve procedures were alive 6 years after surgery. Among patients under 80 years of age, survival favoured those undergoing isolated AVR procedures, but among octogenarians, concomitant CABG surgery did not result in reduced survival. Yamane $\mathrm{K}$ et al [26] published the outcome of a single-centre study of conventional AVR in patients aged 70 or older. In their analysis, patients aged 80-92 who underwent isolated AVR or AVR with CABG showed an acceptable mortality rate of $4.0 \%$, comparable to the $3.8 \%$ mortality rate in patients aged 70-79. Brown et al [27] published the outcomes of isolated AVR in North America by analysing the STS National Database, comprising 108,687 patients, and compared the mortality rates in 1997 with those in 2006. In their analysis, patients aged $70-75$ had a mortality rate of $3.2 \%$ in 1997 and $2.9 \%$ in 2006; for patients aged 80-85, the mortality rate was $6.3 \%$ in 1997 and $4.9 \%$ in 2006 . These improvements in operative outcome over the past decade could be related to multiple factors, including patient selection and perioperative management. A better understanding of the role of preoperative respiratory preparation, improved myocardial protection of otherwise severely hypertrophic myocardium, as well as normothermic cardiopulmonary bypass may have contributed to the improved early postoperative results in recent studies as compared to those several decades ago. Yamane $\mathrm{K}$ et al [26] propose that with the elderly, especially those aged 80 years or older, goal-oriented strategies such as early extubation, judicious sedation management, medication dosage based on renal or liver function, early involvement of physical or occupational therapists, and speech/swallow specialists are all indispensable.

From a patient's perspective, functionality after surgery may be more important than simple survival. Using the Seattle Angina Questionnaire, Huber et al [28] interviewed 136 patients who were 80 years of age at the time of cardiac surgery (isolated CABG, AVR, or AVR $+C A B G)$. They found that $95 \%$ lived in their own homes, and $93 \%$ reported that they had experienced no reduction in their quality of life. Kolh et al [29] interviewed 61 long-term survivors of AVR and found that $92 \%$ of patients believed that having heart surgery at age 80 was a "good choice," with $88 \%$ of patients feeling "as good or better" than they had before surgery. Also, Maillet et al [30] reported results from 84 octogenarians undergoing either AVR or AVR+CABG between 1998 and 2001. The majority (91.1\%) lived in their own homes (compared with $75 \%$ of the general French population aged 80 years), whereas $26.7 \%$ of patients required help with activities of daily living (compared with $35 \%$ to $40 \%$ of the general population). Sundt et al [31] reported functional status and survivorship up to 5 years among 133 patients undergoing AVR with or without CABG. Patient-reported functional status was comparable to the general population.

Because there is no effective medical therapy and balloon valvotomy is not an acceptable alternative to surgery, AVR is the gold standard for the treatment of severe stenosis and must be considered in all elderly patients who have symptoms caused by AS [10]. Age, per se, should not be considered a contraindication for surgery. Decisions should be made on an individual basis, taking into account patients' wishes and cardiac and non-cardiac factors 
[12]. In this population, the need for an emergency operation, or, at the other end of the clinical spectrum, very early intervention at an asymptomatic stage, should be avoided.

The surgical community worked vigorously over the past two decades to reduce the trauma of the conventional aortic valve operation. Ongoing studies of transcatheter aortic valve implantation (TAVI) have demonstrated feasible short- and mid-term results in patients who were not considered suitable candidates for conventional AVR. Minimally invasive approaches like partial upper sternotomy have replaced the conventional complete median sternotomy when performing AVR in many centres. By aiming for smaller incisions, without compromising the quality of the operation and the effectiveness of myocardial protection, improved early outcomes have been achieved.

In a prospective randomised trial, Dogan et al [32] show that minimally invasive AVR can be performed with only slightly longer operative times, good cosmetic results and improved rib cage stability as well as significantly less blood loss. Furthermore, limited surgical access had no negative effects on the patients' neurological outcome nor the efficacy of myocardial protection. More recently, the implantation technique for AVR has also been modified, without compromising the hemodynamic performance of the valve substitute, all in order to reduce implantation times, and therefore reduce ischemia in the myocardium and cardiopulmonary bypass times. In 2009 Martens et al [33] reported on initial clinical experiences with the sutureless, nitinol-stented Enable (Medtronic Inc., Minnesota, USA) aortic valve prosthesis in 32 patients. Implantation time could be significantly reduced, down to $9 \pm 5$ minutes, the first report of multi-centre experience with this particular valve substitute and implantation technique in 140 patients was published in the European Journal of Cardiothoracic Surgery in 2011. Reproducibility as well as feasibility and safety were demonstrated with the ATS 3f Enable ${ }^{\circledR}$ Bioprosthesis. Valve implantation resulted in excellent hemodynamics and significant clinical improvement. Further comparative studies are under way to prove the clinical benefit using this less-time-consuming implantation technique versus the conventional one.

\subsection{High risk patient}

How could we define a cardiac high-risk patient? Which parameters must we consider in order to assess risk? Which is the most accurate assessment tool to calculate a patient's risk?

We could define high risk cardiac patients as those who present several factors that significantly affect their outcome after surgery and could compromise their survival. Multiple series have documented that patients were deemed to have a high risk of operative complications or death on the basis of coexisting conditions such as advanced age, diabetes mellitus, existence of preoperative shock, LVEF $\leq 40 \%(\leq 30 \%)$, preoperative NYHA class III or $\mathrm{IV}$, concomitant CAD, concomitant surgical procedure (CABG, valve surgery or surgery on thoracic aorta), renal failure and chronic obstructive pulmonary disease (COPD). Although attempts have been made to identify the high-risk population for AVR, there is currently no ideal model for precisely identifying high-risk patients. STS-PROM score and the European System for Cardiac Operative Risk Evaluation (EuroSCORE) have been used as part of the inclusion/exclusion criteria for the TAVI trials and to quantify the operative risk of conven- 
tional AVR. Nevertheless, several previous reports on TAVI defined high-risk patients as patients with a logistic EuroSCORE between 10\% and 30\% [18]. Smith et al [34] in a TAVI versus AVR paper published in the New England Journal of Medicine in 2011 used as a guideline a score of at least $10 \%$ on the risk model developed by the STS to define high-risk patients. However, there are multiple additional risk factors, which are not currently considered by existing risk scoring systems; for example the presence of a porcelain aorta and considerations such as social integration, mobility, frailty, and the individual's overall health status must be taken into account, as well as the patient's wishes and expectations. A further definition that must be taken into account for evaluation of those patients who underwent TAVI is that very or extremely high-risk patients are those with a logistic EuroSCORE above $30 \%$ or STS score higher than 15\% (see Table 2). The 2012 ACCF/AATS/SCAI/STS Expert Consensus Document on Transcatheter Aortic Valve Replacement [15] used the term prohibitive risk. This includes some patients for whom surgery might be deemed unsuitable based on the physician's assessment of the patient's risk for surgery; whereas in others, the surgeon may decide that the operation cannot be performed successfully because of technical considerations.

\begin{tabular}{lcc}
\hline & & Risk assessment tool \\
\hline High risk & EuroSCORE & STS score \\
\hline Very or extremely high risk & $10-30 \%$ & $" />10 \%$ \\
\hline
\end{tabular}

Based on the 2012 ACCF/AATS/SCAI/STS Expert Consensus Document on Transcatheter Aortic Valve Replacement [15].

Table 2. Risk Assessment

In the absence of evidence in the literature and recommended guidelines, the determination of inoperability in any given patient depends on the judgement of the Heart team. It is generally agreed that patients with limited life expectancy due to concurrent conditions such as malignant tumours, dementia, primary liver disease or COPD, among others, are not appropriate for AVR. Frailty and poor physical condition are known to result in an inability to recover from major heart surgery such as AVR. These conditions can potentially contribute to increased surgical mortality and morbidity in the elderly. The surgeon may judge a patient inoperable as a result of technical considerations that preclude safe performance of AVR, such as prior mediastinal irradiation, porcelain aorta or severe periannular calcification, severe atheromatous disease, prior cardiac operations, and other conditions such as the internal mammary artery crossing the midline. In summary, a substantial percentage of patients with AS are judged to be inoperable for surgery based primarily on the physician's or surgeon's determination of operative risk and probability of survival [15]. Although some patients may be found to be inoperable for technical and surgical reasons, most inoperable patients are considered to be too ill due to associated comorbid conditions. In conclusion, 
the decision to proceed with AVR or TAVI requires careful weighing of the potential for improved symptoms and survival and the morbidity and mortality of surgery.

\section{Surgical approach}

\subsection{Conventional AVR}

Aortic valve replacement has permitted thousands of lives to be saved since it was first successfully carried out by Harken and Starr in 1960 [35, 36]. Since then, advances in prosthetic technology including improved hemodynamics, durability and thromboresistance, and techniques in cardiac surgery such as cardioplegia, management of the small aortic root, and replacement of associated aortic aneurysm have resulted in improvements in both operative and long-term results.

The conventional approach to AVR is the following: A mid-line incision and sternotomy is made and a pericardial well created. The patient is cannulated via the aorta and a single atrial venous cannula. After cross-clamping of the aorta, a transverse aortotomy is made approximately $1 \mathrm{~cm}$ above the take-off of the right coronary artery, slightly above the level of the sinotubular ridge (Figure. 3).

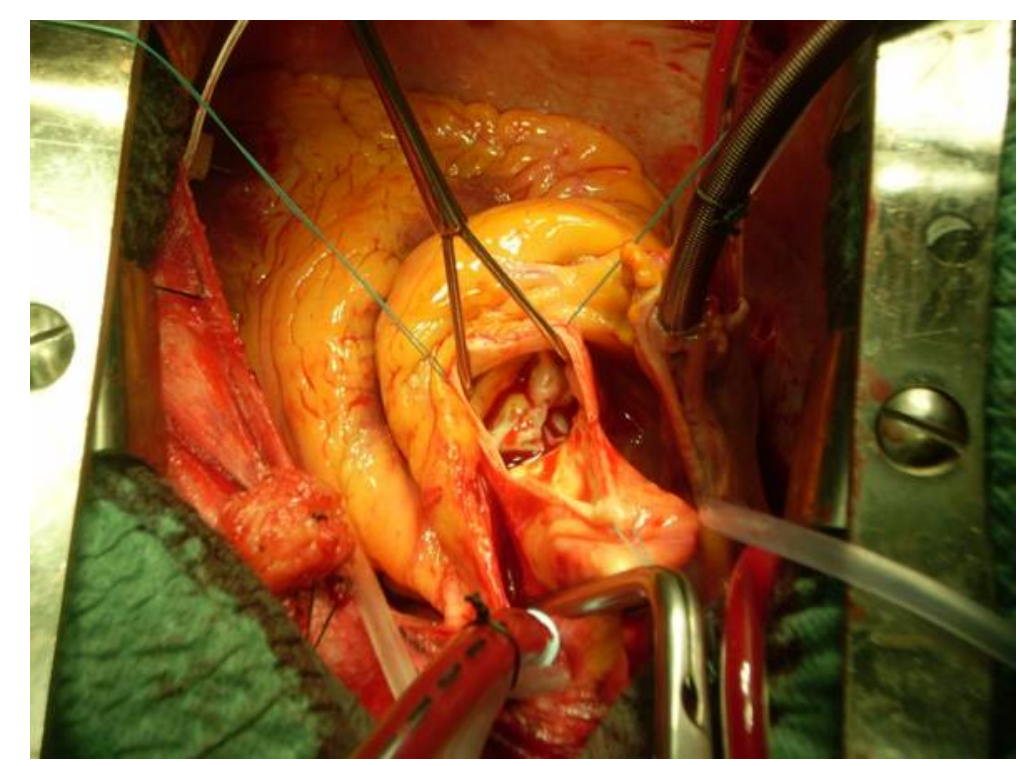

Figure 3. Transverse aortotomy

The incision is extended three-quarters of the way around the aorta, leaving the posterior one-quarter of the aorta intact allowing excellent visualization of the native aortic valve and 
annulus. The leaflets of the aortic valve are excised to the level of the annulus and the annulus is thoroughly debrided of any calcium. Braided 2-0 sutures with pledgets are applied. Beginning at the non-coronary commissure, the annulus is encircled with interrupted mattress sutures (Figure 4) extending from the ventricular to the aortic surface.

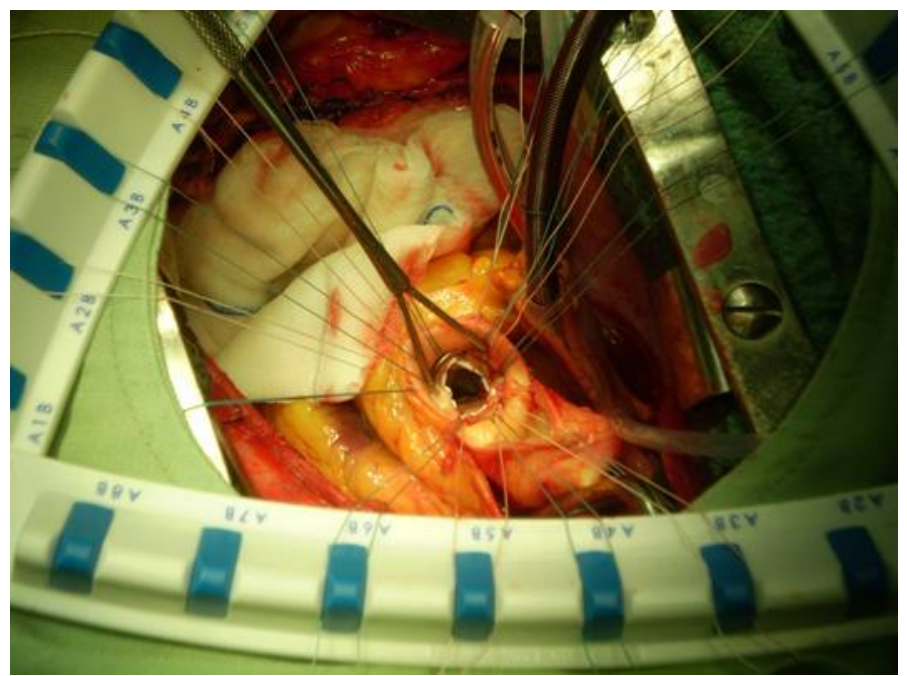

Figure 4. Aortic annulus encircled with interrupted mattress sutures

Next, each half of the suture bundles are implanted in the sewing ring and the prosthesis seated. The sutures are tied first at the left coronary cusp extending to the mid-portion of the right coronary cusp. Lastly, the sutures of the non-coronary cusp are secured, seating the valve appropriately. In case of mechanical valve prosthesis leaflet motion should always be checked and the surgeon must be assured that the coronary arteries are not obstructed. The aortotomy is closed with a double layer of polypropylene suture consisting of an underlying mattress suture and a more superficial over-and-over suture.

\subsubsection{Conventional AVR results}

Regardless of surgical approach, elected AVR is the gold standard for the treatment of severe AS. Several studies have shown acceptable short- and long-term outcomes, as well as improved quality of life in elderly patients. Although the proportion of elderly patients with multiple comorbidities is expanding, operative outcomes following AVR were still improving in the past decade. Recent series such as Likosky et al [25], report 30-day mortality among patients who underwent isolated AVR of $3.7 \%$ for patients $<80,6.7 \%$ in the 80 to 84 age group, and $11.7 \%$ in those ages $>85(\mathrm{P}<0.001)$. Among patients undergoing AVR+CABG, $6.2 \%$ of patients $<80$ years died within 30 days, $9.4 \%$ among those 80 to 84 , and $8.5 \%$ of patients $\geq 85$ years $(\mathrm{P}=0.01)$. Also M. Di Eusanio et al [37] published a multi-centre study including 638 octogenarians who underwent AVR from an Italian regional cardiac surgery 
registry (2003-2009), They report hospital mortality of 4.5\%, which favourably compares with those reported in other series (ranging from $4.3 \%$ to $13.7 \%$ ). Recent surgical series [3, 38] report operative mortality rates for aortic valve replacement as low as $1 \%$, increasing to $9 \%$ in higher-risk patients. Long-term survival after valve replacement is $80 \%$ at 3 years, with an age-corrected postoperative survival that is nearly normalized. Significant postoperative morbidity, such as thromboembolism, haemorrhagic complications from anticoagulation, prosthetic valve dysfunction, and endocarditis, are rare and occur at a rate of $2 \%$ to $3 \%$ per year [38]. These improvements in operative outcome could be related to multiple factors, including patient selection and perioperative management.

A number of studies have also examined outcomes of AVR conducted with concomitant CABG surgery. With few exceptions, concomitant CABG surgery does not increase a patient's operative risk. Considering the mounting evidence for the acceptable perioperative outcomes after AVR with or without concomitant CABG in the elderly, perhaps the fact that as many as one-third of patients $>80$ years of age with severe aortic stenosis are still denied surgery because of their age is due at least in part to the lack of evidence for long-term outcomes. Likosky et al [25] published the outcome of the very elderly undergoing aortic valve surgery comprising 7584 patients, including 815 over the age of 80 . They have demonstrated that aortic valve replacement with or without concomitant CABG is a safe and effective option for elderly patients with severe aortic stenosis. Specifically, more than half of the patients undergoing aortic valve procedures were alive 6 years after surgery. Although concomitant $\mathrm{CABG}$ adds a slight mortality risk in the immediate postoperative period, it does not appreciably affect long-term survival among patients older than 80 years.

Survival has been also improved in elderly patients who underwent AVR. Asimakopoulos et al [39] reviewed United Kingdom Heart Valve Registry data from 1100 patients $>80$ years of age who underwent AVR from January 1986 to December 1995. They reported 30-day mortality as $6.6 \%$ with actuarial survival of $89 \%, 79.3 \%, 68.7 \%$, and $45.8 \%$ at $1,3,5$, and 8 years, respectively. Likosky et al [25] report a 6-year survival of $54.7 \%$ in patients aged 80 to 84 following AVR and 53.3\% in patients aged 80 to 84 following AVR+CABG. Yamane et al [26] published their single centre study in 2011, reporting Survival at 1, 3, 5, and 10 years in patients aged $70-79$ as $91.6 \%, 85.1 \%, 77.2 \%$, and $38.0 \%$, respectively, as compared with $84.1 \%, 75.7 \%, 63.0 \%$, and $21.7 \%$ in patients aged $80-92$ ( $\mathrm{P}=0.002)$. More recently M. Di Eusanio et al [37] report a 1, 3 and 6 year survival of $91.3 \%, 80.6 \%$ and $67.5 \%$ respectively in octogenarian patients who underwent isolated AVR.

In several studies, estimates of quality of life, as measured by NYHA functional class improvement, autonomy or satisfaction after receiving surgery have shown excellent functional recovery after AVR in patients $>80$ years (also see Elderly patient). Wu et al [40] in a recent study, determining the economic value of the additional life given to patients undergoing AVR, concluded that AVR is cost-effective for all ages, and still worthwhile in octogenarian and nonagenarian patients.

In conclusion, conventional AVR in selected octogenarians has similar outcomes to those in "younger" elderly patients, with good mid-term survival and excellent functional recovery 
with a marked improvement in quality of life; in fact, their level of function and quality of life are the same as a general population of age-matched subjects.

\subsection{Minimally Invasive Surgical (MIS) approaches}

MIS approaches appear to improve the results observed in conventional surgery. The latter shows good results with acceptable morbidity and mortality rates in most cases, including in patients with aortic valve disease, however, in some subgroups of patients these outcomes tend to be worse. Minimally invasive surgery aims to minimise the degree of surgical intrusiveness. Currently there are several surgical approaches. A partial upper sternotomy is the most frequently used incision for a minimally invasive approach to the aortic valve and this is usually carried out via a parasternal incision over the second and third intercostal space, depending on the patient's anatomy as observed in preoperative imaging studies such as CT. The partial sternotomy is also frequently used, and there are several possible approaches. The table below summarises the various possible techniques (Table 3).

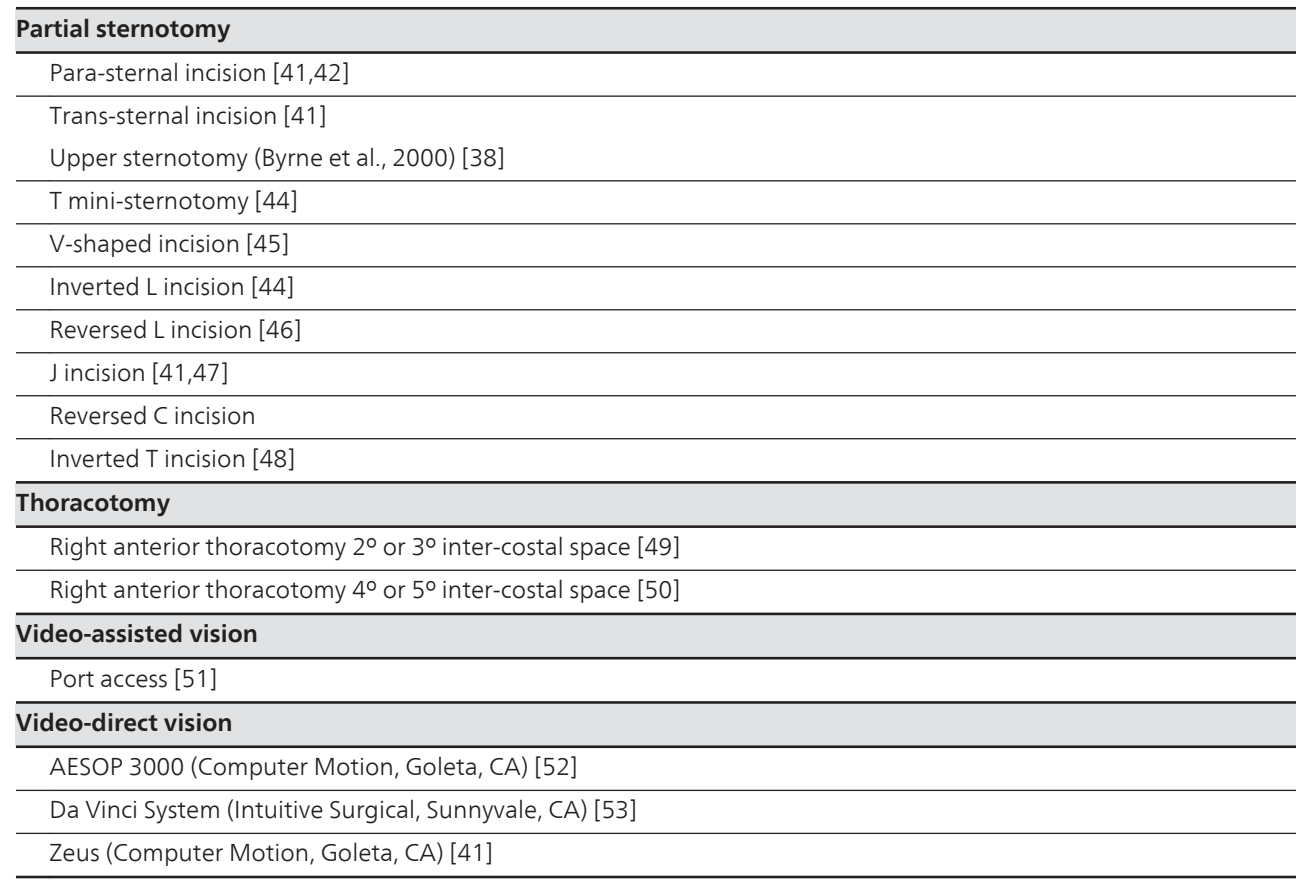

Bustamante et al., 2012 [54]

Table 3. Minimally Invasive Approaches.

The "J" incision is the most widely used approach among the partial sternotomy approaches (Figure 5 \& 6). 

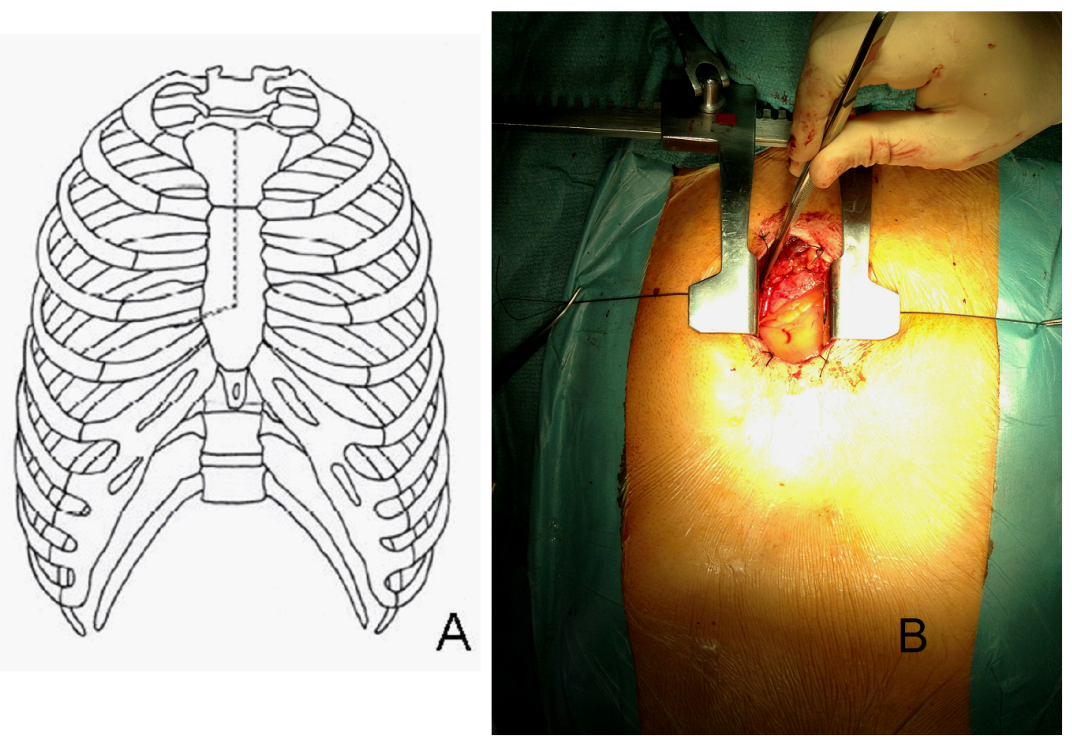

Figure 5. A \& B: Reversed L incision.

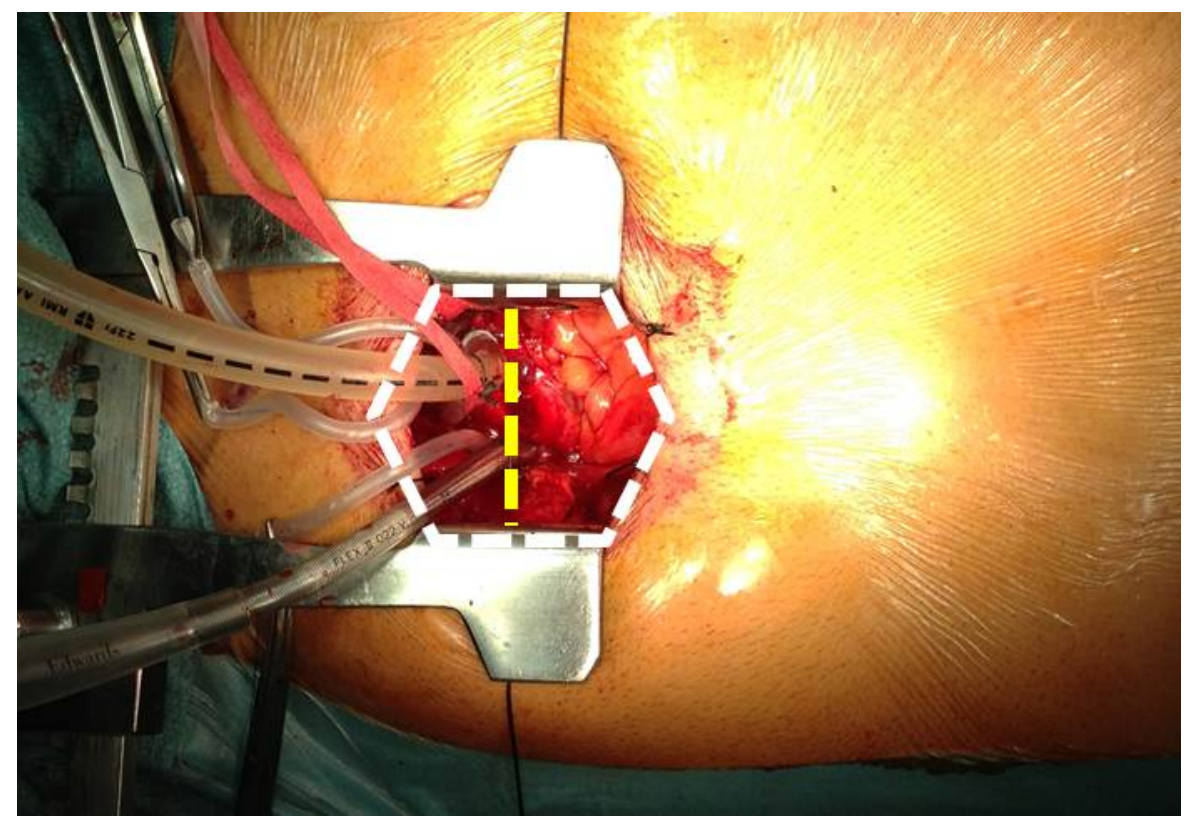

Figure 6. Operative field distribution from surgeon view. 
However there are other approaches that are gaining popularity and some groups are beginning to use it quite often, so is the case of the right anterior thoracotomy through $2^{\circ}$ or $3^{\circ}$ inter-costal space (Figure 7).

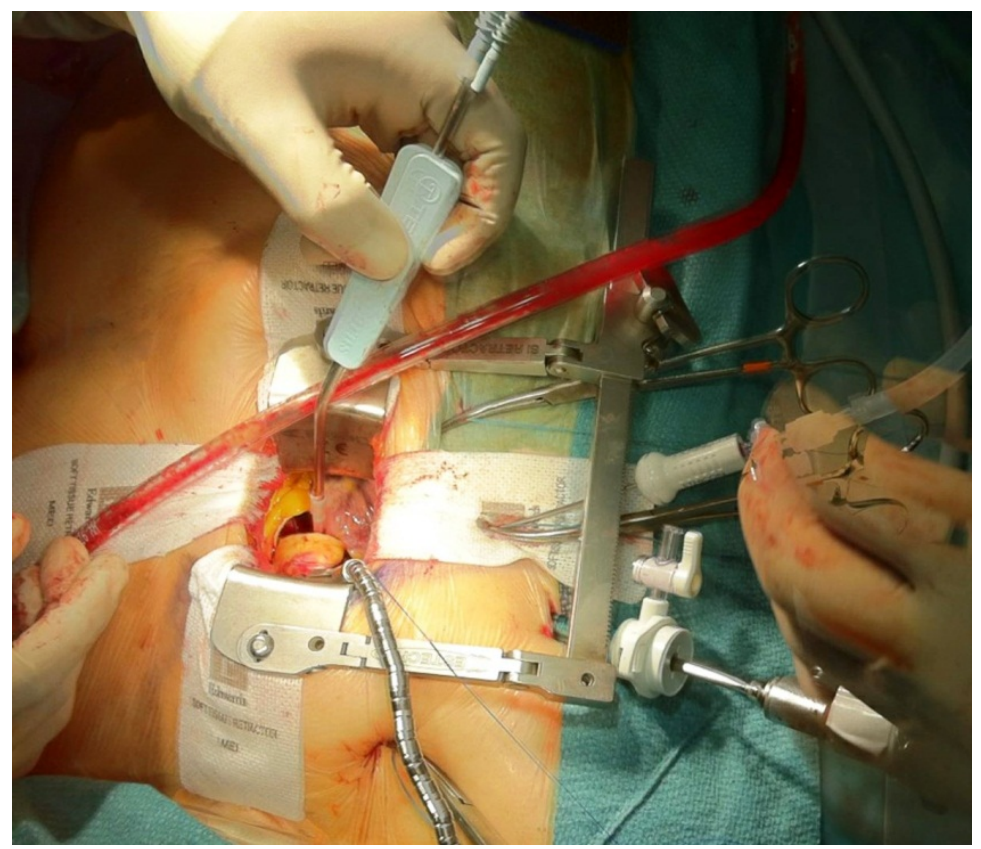

Figure 7. Right anterior thoracotomy through $2^{\circ}$ or $3^{\circ}$ inter-costal space.

Some controversy exists as to the benefits of these approaches. There are currently very few randomized studies able to answer this question and those that do exist have certain limitations $[55,56]$. However, in the medical literature we do find numerous articles that report broad series of patients in which the effects can be observed and several aspects of these approaches can be compared to conventional approaches.

A series of advantages traditionally exist in the application of MIS for aortic valve replacement. There is no methodological uniformity across the studies that have been carried out, which sometimes complicates comparison between studies and makes it difficult to draw conclusions about the impact of these approaches on patient treatment. This is due to the fact that the aspects considered by the different studies differ in some cases. For example, some focus on length of hospitalization and specific complications and others give more relevance to surgical aspects such time spent with extracorporeal circulation or clamping. In summary, we can say that there is a group of patients about which there is a certain consensus as to the benefits of the MIS approaches. This group includes the elderly [50], and patients who have previously undergone interventions involving myocardial revascularisation [43]. In the first case the benefit fundamentally lies in the reduction of surgical aggression in 
cases where patients are more susceptible to developing post-operative complications, leading to a much faster functional recovery time compared to patients subjected to conventional interventions. In the second case the benefit lies in the fact that it is not necessary to dissect the mediastinal structures, thus avoiding the risk of damaging coronary implants, and the complications that would entail $[57,58]$.

\subsubsection{Advantages and disadvantages of MIS approaches in aortic stenosis}

In other patients there are arguments in favour of MIS. Benefits have been observed in certain aspects such as:

- Reduction in bleeding in surgery and therefore in the use of hemoderivatives. There are also discrepancies in this aspect, as while some studies indicate the benefit [55, 59-61], others, such as Stamou et al [44] do not observe this effect. A possible explanation for this disparity of results is that in the assessment of reduced post-operative bleeding, no prior adjustments for risk factors for post-operative bleeding were made. The debate is further complicated by the fact that Dogan et al [32], observed differences in the reduction of post-surgical bleeding in a randomised study. In our group we did observe a statistically significant reduction in blood loss during surgery and in the need for hemoderivatives.

- Reduction in the pain perceived by the patient. Numerous studies indicate this benefit $[55,62,63]$ which is based on a reduction in the distension of costovertebral ligaments and traction of the brachial plexus. This results in reduced consumption of analgesic pharmaceuticals by the patient.

- Less reduction in tidal lung volume, thus reducing the appearance of respiratory complications such as atelectasis by maintaining the integrity of the thorax [56].

- Better aesthetic results. This is one of the clear benefits of the technique, due to the reduced size of the surgical incisions and their relocation to less visible areas.

- There are other benefits, such as the reduction in complications in the surgical wound/ infections. Grossi et al [64] observe an incidence of infection of $0.9 \%$ for minimally invasive approaches as against $5.7 \%$ in cases of patients with the approach by sternotomy, $\mathrm{p}=0.05$. It has been observed that this difference increases in elderly patients (1.8 and $7.7 \%$ respectively). Other authors observe that in comparison with the classical approach there is a lesser incidence of infectious complications $[65,66]$.

A certain consensus exists around the benefits mentioned above. There is also the question of the impact of MIS on duration of surgery. There is disparity in the results found in the literature. Along with other research groups, we observed that, once the learning curve has been overcome, these times tend to equal out and there is no significant difference to be observed between the different approaches. Studies that support an increase in the time for cardiopulmonary bypass and aortic clamping are Farhat et al, Detter et al, de Vaumas et al, and Stamou et al. [44, 46, 48, 67]; contradictory results can be found in Corbi et al., Sharony et al or the randomised study by Bonachi et al. [45, 50,55]. Another aspect that is highly valued in MIS surgery is the impact it has on the duration of hospitalisation and time spent in 
intensive care units. This has been taken into consideration in reducing the cost of the process, in a context of increased life expectancy and rising healthcare costs. In terms of patient treatment it is relevant in that the reduction of both is accompanied by a lesser incidence of other complications, basically infections, particularly respiratory infections, surgical wound infections and urinary tract infections.

\subsection{Transcatheter Aortic Valve Replacement (TAVR)}

Transcatheter aortic valve implantation (TAVI) was developed as an alternative to AVR in the very or extremely high-risk patient population. The first implant in man was performed by Cribier [68] in 2002, using a balloon expandable frame and equine valve. Since the introduction of minimally invasive and catheter-based therapies, patients want less invasive options for all types of medical procedures including general surgical, orthopaedic, spinal, and urological operations with the goal of decreasing morbidity and mortality and shortening recovery time. Other issues with traditional aortic and mitral valve surgery include the fact that patients may not even be offered operation; in multiple series from different centres and in different countries, up to $40 \%$ of patients with severe aortic stenosis are treated medically $[69,70]$. Some of these patients may be deemed to be too sick for surgery because of associated medical comorbidities, and some may be considered too old. Finally, some who may benefit the most from an operation may decline surgery even though they develop irreversible damage from the valve lesion that could have been treated. These factors have led to the continuous development of less invasive strategies with lower mortality, lower morbidity, and less invasiveness [71]. Transcatheter aortic valve replacement seems to offer a new window of treatment for those patients with severe aortic valve stenosis that are either extremely high-risk or inoperable for conventional aortic valve replacement. Today around 40000 patients have received a transcatheter aortic valve implantation (TAVI) worldwide. Multiple single- and multi-centre registries, and a single randomized trial, the PARTNER trial (Placement of AoRTic TraNscathetER Valve Trial), have documented favourable outcomes using a wide spectrum of endpoints, including survival, symptom status, quality of life, and need for repeat hospitalization.

\subsubsection{Implantation techniques}

TAVI is currently carried out using two main approaches (retrograde transfemoral and antegrade transapical), which share the same main principles. Trans-axillary artery or transaortic are other approaches that are gaining popularity when the transfemoral approach is not feasible. Specific anatomic issues must be considered in device design. These include the rigid structure and pattern of the valvular calcification and the aortic annulus, and the need for as full an apposition as possible to the annulus in an attempt to minimize periprosthetic leaks. In the case of eccentric, bulky calcifications, this may be difficult. The close proximity to the coronary ostia, the width and height of the sinuses, the membranous ventricular septum with the His bundle and the anterior leaflet of the mitral valve are also important anatomical considerations. In addition, the size and degree of severity of peripheral arterial disease are all factors that could limit catheter size [15]. It is therefore highly recommended to perform 
an adequate preoperative assessment of the degree of peripheral arterial disease through imaging studies such as CT (Figure 8).

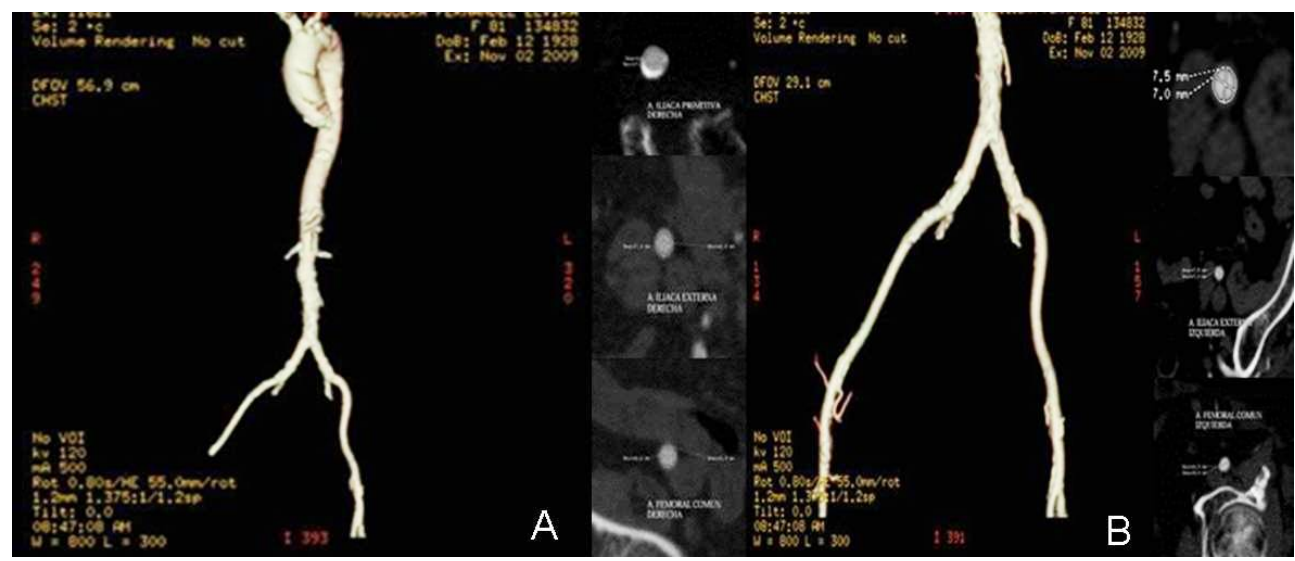

Figure 8. (A) CT reconstruction of the aorta. (B) CT reconstruction of iliofemoral arteries

Most teams perform the procedure under general anaesthesia, although sedation and analgesia may suffice for the transfemoral approach. Peri-procedural transoesophageal echocardiography (TEE) monitoring is desirable to correctly position the valve as well as to detect complications. After crossing the aortic valve, Balloon aortic valvuloplasty is performed to pre-dilate the native valve and serve as a rehearsal for TAVI. Simultaneous rapid pacing decreases cardiac output, stabilizing the balloon during inflation. Normal blood pressure must be completely recovered between sequences of rapid pacing. In order to position the prosthesis at the level of the aortic valve annulus different methods can be used, such as fluoroscopy to assess the level of valve calcification (Figure 9); aortography, using different views, performed at the beginning of the procedure and repeated with the undeployed prosthesis in place, to determine the position of the valve and the plane of alignment of the aortic cusps; and echocardiography. TEE is particularly helpful in cases with moderate calcification.

Three dimensional real-time TEE seems to provide extra information to the teams that use it. When positioning is considered correct, the prosthesis is released. Rapid pacing is used at this stage for balloon-expandable devices but not for self-expanding ones. Immediately after TAVI, aortography and, whenever available, TEE or, in the absence of TEE, Transthoracic echocardiogram(TTE) are performed to assess the location and degree of aortic regurgitation and the patency of the coronary arteries, and to rule out complications such as haemopericardium, and aortic dissection. The hemodynamic results are assessed using pressure recordings and/or echocardiography. After the procedure, the patients should stay in intensive care for at least 24 hours and be closely monitored for several days, particularly as regards hemodynamics, vascular access, rhythm disturbances (especially late atrioventricular block), and renal function. 


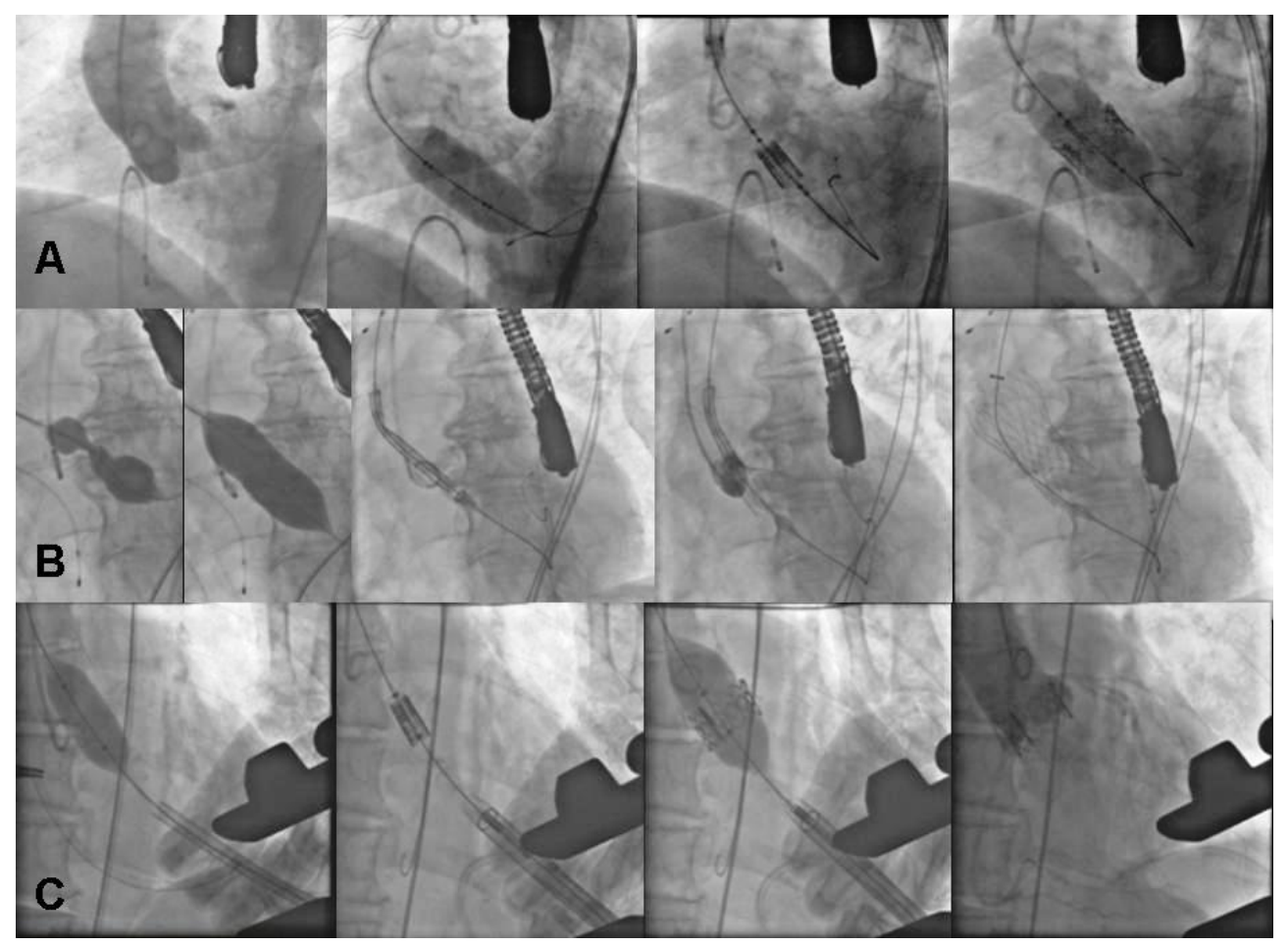

Figure 9. First row (A). Edwards Sapiens transfemoral implantation. Second row (B). Transfemoral Corevalve implantation. Third row (C). Edwards Sapiens transapical implantation.

The specific issues related to the different approaches include the following: In the transfemoral approach, close attention should be paid to the vascular access. The common femoral artery can be either prepared surgically or approached percutaneously. Echo-guided femoral access could be useful. Manipulation of the introductory sheaths should be careful and fluoroscopically guided. Depending on the size of the device, closure of the vascular access can be effected surgically or using a percutaneous closure device. Femoral access and cardiopulmonary bypass should be on standby for patients for whom surgical conversion is an option in case of complications.

The transapical approach requires an antero-lateral mini-thoracotomy (Figure 10), pericardiotomy, identification of the apex, and then puncture of the left ventricle using a needle through purse-string sutures. Subsequently, an introductory sheath is positioned in the LV, and the prosthesis is implanted using the antegrade route. 


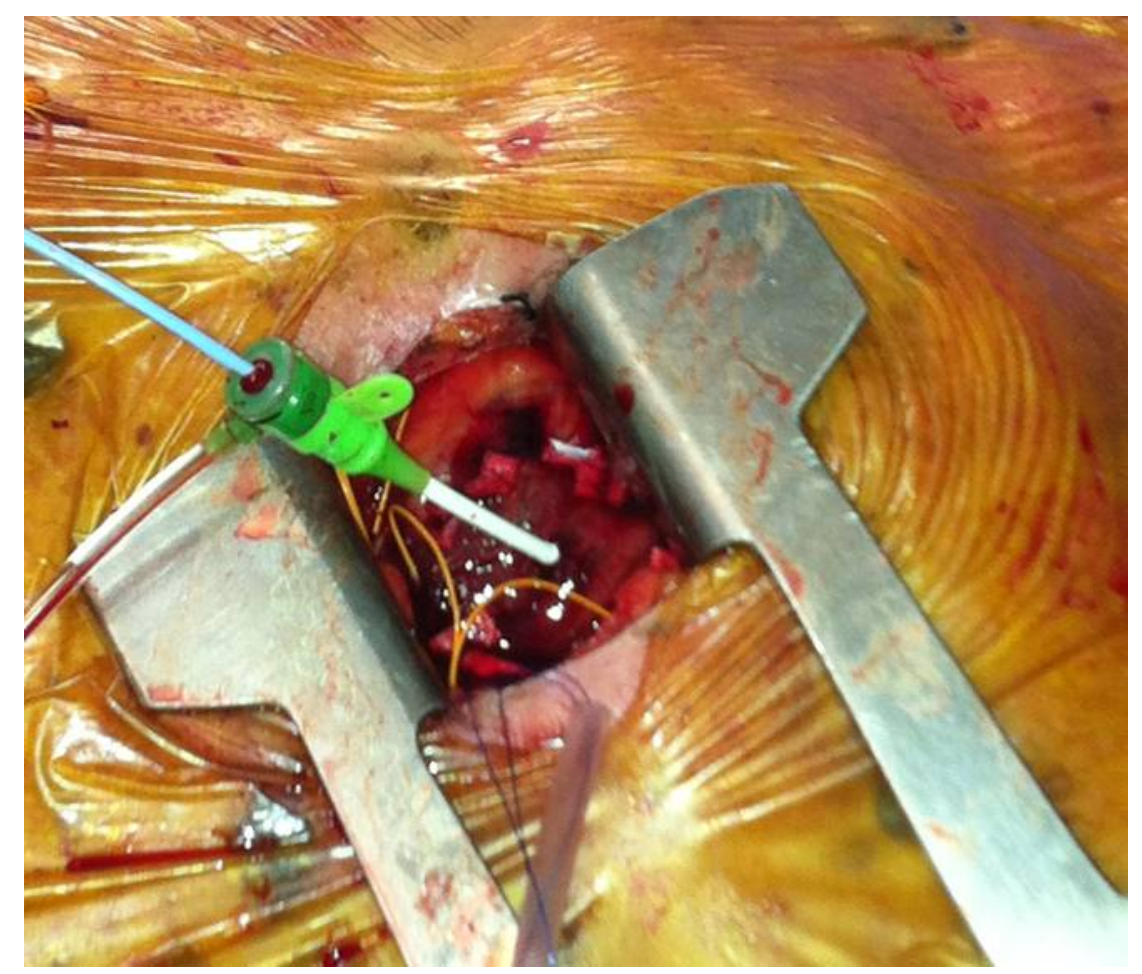

Figure 10. Anterior minitoracotomy for transapical approach of a TAVI procedure.

\subsubsection{TAVR results}

The PARTNER trial has been followed with great interest. The PARTNER trial was basically 2 parallel trials: 1) PARTNER Cohort A, which randomized high-risk surgical patients to either traditional aortic valve replacement or to TAVI by either a transfemoral or transapical approach; and 2) PARTNER Cohort B in which patients who were inoperable were randomized to either a TAVR by a transfemoral approach or to conventional medical therapy, which typically consisted of balloon aortic valvuloplasty.

Screening required evaluation by 2 experienced cardiac surgeons to agree on the surgical risk using the STS Predicted Risk of Mortality score and was rigorous, with approximately one-quarter to one-third of screened patients subsequently enrolled. The primary endpoint was death from any cause at 1 year. The results of PARTNER Cohort B included 358 patients deemed unsuitable for conventional aortic valve replacement because of predicted probability of $\geq 50 \%$ mortality or the risk of a serious irreversible complication within 30 days. At 1 year, all-cause mortality with TAVR was $30.7 \%$ versus $50.7 \%$ with medical therapy (hazard ratio: $0.55,95 \%$ confidence interval: 0.40 to 0.74$)$. Despite the marked improvement in survival and event-free survival, there were some significant safety hazards, particularly a 
higher incidence of major strokes (5.0\% versus $1.1 \%)$ as well as increased major vascular complications $(16.2 \%$ versus $1.1 \%$ ) with TAVR, both of which may adversely impact early and longer-term outcome. Longer-term outcomes will be required. These results were received enthusiastically; however, they have important limitations. Firstly, they can be applied only in patients similar to those in the study (i.e., those patients deemed to be inoperable). Secondly, they are the result of treatment by very experienced operators working as a heart team in a hybrid operating room or similar facility with a specific device and do not necessarily apply to other devices.

The results of the PARTNER Cohort A trial also have important implications. The primary endpoint of the trial was met, with TAVR found not to be inferior to aortic valve replacement for all-cause mortality at 1 year (TAVR versus aortic valve replacement, $24.2 \%$ versus $26.8 \%$, respectively, $\mathrm{p}=0.001$ for non-inferiority). Death at 30 days was lower than expected in both arms of the trial: TAVR mortality (3.4\%) was the lowest reported in any series, despite an early generation device and limited previous operator experience. Aortic valve replacement mortality (6.5\%) was lower than the expected operative mortality (11.8\%). Furthermore, both TAVR and aortic valve replacement were associated with important but different peri-procedural hazards: major strokes at 30 days $(3.8 \%$ versus $2.1 \%, \mathrm{p}=0.20)$ and 1 year $(5.1 \%$ versus $2.4 \%, \mathrm{p}=0.07)$, and major vascular complications were more frequent with TAVR $(11.0 \%$ versus $3.2 \%$, $<<0.001)$. Major bleeding $(9.3 \%$ versus $19.5 \%, \mathrm{p}<0.001)$ and new onset atrial fibrillation $(8.6 \%$ versus $16.0 \%, \mathrm{p}<0.001)$ were more frequent with aortic valve replacement.

Rates of stroke were similar whether the access was transfemoral or transapical. Bioprosthetic-valve gradients and orifice areas were slightly better after transcatheter replacement than after surgical replacement, probably because of the less bulky support frame with transcatheter replacement [34]. However, transcatheter replacement resulted in much more frequent paravalvular aortic regurgitation. Although this condition was stable at 1 year, repeat intervention was required in some cases. A reduction in the incidence and severity of paravalvular AR represents an obvious target for technical improvements in the design of transcatheter valves and of implantation techniques [24]. Clinical benefits of transcatheter replacement included significantly shorter stays in the intensive care unit and in hospital. In addition, the NYHA functional class and 6-minute walk distance were strikingly improved at 1 year [34]. Transcatheter aortic valve implantation by means of either the transfemoral or the transapical approach is a reasonable and promising treatment option for patients who are at high risk or had been refused for conventional AVR. Recommendations made to individual patients must balance the appeal of avoiding the known risks of open-heart surgery against the less invasive transcatheter approach, which has different and less well understood risks, particularly with respect to stroke and paravalvular aortic regurgitation.

\section{New prostheses in mini-invasive approaches}

These prostheses were designed by industry with a view to facilitating the implantation of the prosthesis through conventional surgery; that is to say, using a cardio-pulmonary by- 
pass and aortic clamping. The gold standard for the use of these prostheses is in association with MIS approaches, providing a reduction in surgical aggression in addition to the reduction in ECC and aortic clamping time, the consequences of which we have already examined. These designs have the common feature of being expandable, anchoring themselves to the aortic ring in a similar way to the devices used in TAVI.

To date there are three commercially available models: 3f Enable ${ }^{\circledR}($ Medtronic Inc, Minneapolis, MN), Perceval S (Sorin Group Cardio Srl, Sallugia, Italy) and Intuity (Edwards Lifesciences, Irvine, California). These differ from each other in a few characteristics.

3f Enable ${ }^{\circledR}$ aortic bioprosthesis (Figure 11): This prosthesis is especially indicated in patients with small aortic annulus where the possibility of having a severe mismatch is high with the use of conventional prosthesis. Several studies report an acceptable hemodynamic behavior with this type of prosthesis. Furthermore, there is no need to match the measure between the annulus and the sinotubular junction, because the prosthesis is anchored only to the annulus. Of the three prostheses this is the oldest and different models have been developed since its initial commercialisation with a view to improving hemodynamics, durability and facilitating surgeons in its implantation [72-74]

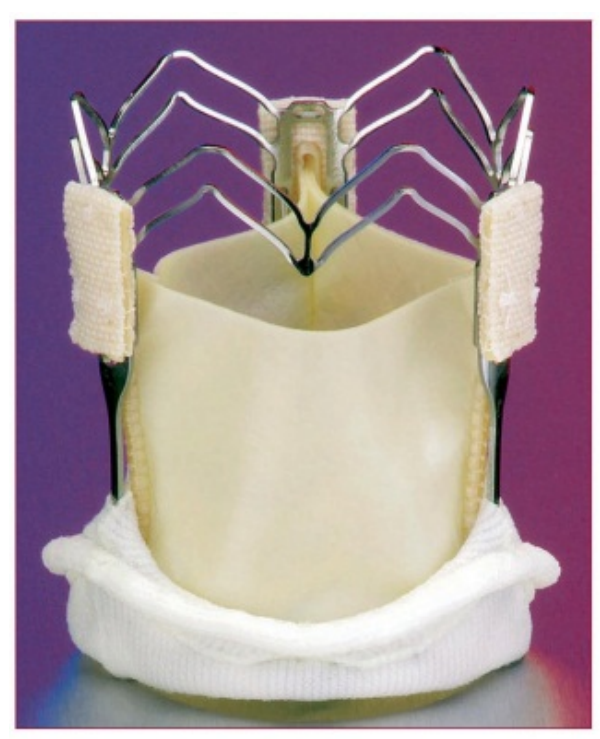

Figure 11. Enable ${ }^{\circledR}$ (Medtronic Inc, Minneapolis, MN)

Perceval S (Sorin Biomedica Cardio Srl, Sallugia, Italy) (Figure 12): Prosthesis aimed at patients with a high surgical risk in which a reduction in surgery time may have a significant impact, for patients where it is necessary to carry out mixed procedures, and patients undergoing re-intervention, and patients with a small aortic ring, because of the hemodynamic characteristics of the prosthesis $[75,76]$ 


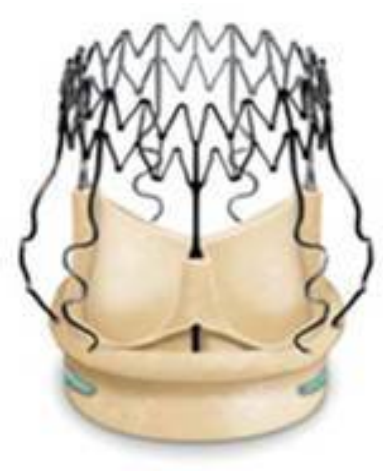

Figure 12. Perceval S (Sorin Biomedica Cardio Srl, Sallugia, Italy)

Intuity (Edwards Lifesciences, Irvine, California) (Figure 13): Of these three prostheses this is the most recently commercialised and results as to its hemodynamic profile and durability in clinical practice are not available. Arguments in its favour, as put forward by the company, are the conjunction between the Edwards Perimount bioprosthesis, the clinical and hemodynamic results of which are widely known, and the experience in the development of new prostheses such as the Sapien transcatheter. The mode of implantation for this prosthesis allows the aortic clamping and extracorporeal circulation times to be reduced. For a number of reasons, one of the most important being ischemic reperfusion, these two variables are known to be directly related to the surgical morbidity and mortality of procedures, which is why this model may be attractive, in addition to the comfort of implantation, as it does not require stitches in the aortic ring.

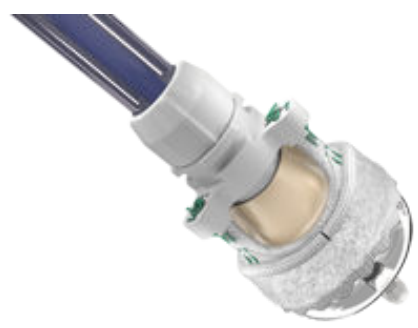

Figure 13. Intuity (Edwards Lifesciences, Irvine, California)

The disadvantage of these prostheses is their cost, as they ultimately increase resource consumption. Results for hemodynamics and durability are becoming better understood as preliminary studies are published. From the beginning we find data in the literature relating to safety and effectiveness in the implantation of aortic valve replacements. Some of the complications associated with their use, such as perivalvular leaks are understood to be intimately related to the decalcification of the ring; in some cases, it has been possible to correct 
other complications, such as bad positioning, with new designs being applied to the already existing prosthetics [77]

\section{Conclusions}

Medical science is progressing faster than ever and the field of cardiovascular disease is one of its greatest exponents. Patient care and treatment must adapt to changing patient characteristics as well as to new technologies and treatment options. In the case of aortic valve disease, whose prevalence is booming in the western world, we must be capable of a comprehensive approach to ensure optimal results and efficient use of resources. Currently, age, per se, is not a contraindication for the treatment of aortic valve disease; hence a thorough assessment should be undertaken to design the best therapeutic approach for high-risk patients. Understanding of treatment options of this disease has increased. New devices have been developed and advances have been made in perioperative management of cardiac surgical patients. Nevertheless, there is still room for improvement in this interesting field of cardiac surgery.

\section{Author details}

Omer Leal ${ }^{1}$, Juan Bustamante ${ }^{1^{*}}$, Sergio Cánovas ${ }^{2}$ and Ángel G. Pinto ${ }^{3}$

*Address all correspondence to: jbustamantemunguira@gmail.com

1 Department of Cardiovascular Surgery, Hospital Universitario La Princesa, Madrid, Spain

2 Department of Cardiac Surgery, Hospital General Universitario de Valencia, Valencia, Spain

3 Department of Cardiac Surgery, Hospital Universitario Gragorio Marañon, Madrid, Spain

\section{References}

[1] Schmitto J.D., Mohr F.W., Cohn L.H. Minimally invasive aortic valve replacement: how does this perform in high-risk patients? Curr Opin Cardiol. 2011; 26(2):118-122.

[2] Chambers J.B. Aortic stenosis. Eur J Echocardiogr. 2009; 10(1):i11-9.

[3] Freeman RV, Otto CM. Spectrum of calcific aortic valve disease: pathogenesis, disease progression, and treatment strategies. Circulation. 2005 Jun 21;111(24): 3316-3326. 
[4] Otto CM, Lind BK, Kitzman DW, Gersh BJ, Siscovick DS. Association of aortic-valve sclerosis with cardiovascular mortality and morbidity in the elderly. N Engl J Med. 1999 15;341(3):142-147.

[5] Kurtz CE, Otto CM. Aortic stenosis: clinical aspects of diagnosis and management, with 10 illustrative case reports from a 25-year experience. Medicine (Baltimore). 2010;89(6):349-379.

[6] Steadman CD, Ray S, Ng LL, McCann GP. Natriuretic peptides in common valvular heart disease. J Am Coll Cardiol 2010;55:2034-2048.

[7] Bergler-Klein J, Klaar U, Heger M, Rosenhek R, Mundigler G, Gabriel H, et al. Natriuretic peptides predict symptom-free survival and postoperative outcome in severe aortic stenosis. Circulation 2004; 109:2302-2308.

[8] Monin JL, Lancellotti P, Monchi M, Lim P, Weiss E, Pie'rard L, et al., Risk score for predicting outcome in patients with asymptomatic aortic stenosis. Circulation 2009;120:69-75.

[9] Lancellotti P, Moonen M, Magne J, O'Connor K, Cosyns B, Attena E, et al., Prognostic effect of long-axis left ventricular dysfunction and B-type natriuretic peptide levels in asymptomatic aortic stenosis. Am J Cardiol 2010; 105:383-388.

[10] Bonow RO, Carabello BA, Chatterjee K, de Leon AC Jr, Faxon DP, Freed MD, et al. 2008 focused update incorporated into the ACC/AHA 2006 guidelines for the management of patients with valvular heart disease: a report of the American College of Cardiology/American Heart Association Task Force on Practice Guidelines (Writing Committee to revise the 1998 guidelines for the management of patients with valvular heart disease). Endorsed by the Society of Cardiovascular Anesthesiologists, Society for Cardiovascular Angiography and Interventions, and Society of Thoracic Surgeons. J Am Coll Cardiol. 2008 23;52(13):e1-142.

[11] Vahanian A, Alfieri O, Andreotti F, Antunes MJ, Barón-Esquivias G, Baumgartner H, et al. Guidelines on the management of valvular heart disease (version 2012): The Joint Task Force on the Management of Valvular Heart Disease of the European Society of Cardiology (ESC) and the European Association for Cardio-Thoracic Surgery (EACTS). Eur J Cardiothorac Surg. 2012 27. doi:10.1093/eurheartj/ehs109.

[12] Vahanian A, Baumgartner H, Bax J, Butchart E, Dion R, Filippatos G, et al. Guidelines on the management of valvular heart disease: The Task Force on the Management of Valvular Heart Disease of the European Society of Cardiology. Eur Heart J. 2007;28(2):230-268.

[13] Baumgartner H, Hung J, Bermejo J, Chambers JB, Evangelista A, Griffin BP, et al. American Society of Echocardiography; European Association of Echocardiography. Echocardiographic assessment of valve stenosis: EAE/ASE recommendations for practice. J Am Soc Echocardiogr. 2009;22(1):1-23.

[14] Ross J Jr, Braunwald E. Aortic stenosis. Circulation. 1968;38(1 Suppl):61-67. 
[15] Holmes DR Jr, Mack MJ, Kaul S, Agnihotri A, Alexander KP, Bailey SR, et al. 2012 ACCF/AATS/SCAI/STS expert consensus document on transcatheter aortic valve replacement: developed in collaboration with the American Heart Association, American Society of Echocardiography, European Association for Cardio Thoracic Surgery, Heart Failure Society of America, Mended Hearts, Society of Cardiovascular Anesthesiologists, Society of Cardiovascular Computed Tomography, and Society for Cardiovascular Magnetic Resonance. Ann Thorac Surg. 2012;93(4):1340-1395.

[16] Grant SW, Hickey GL, Dimarakis I, Trivedi U, Bryan A, Treasure T, et al. How does EuroSCORE II perform in UK cardiac surgery; an analysis of 23740 patients from the Society for Cardiothoracic Surgery in Great Britain and Ireland National Database. Heart. 2012 Aug 21. doi:10.1136/heartjnl-2012-302483.

[17] Frilling B, von Renteln Kruse W, Riess FC. Evaluation of operative risk in elderly patients undergoing aortic valve replacement: the predictive value of operative risk scores. Cardiology. 2010;116(3):213-218.

[18] Thielmann M, Wendt D, Eggebrecht H, Kahlert P, Massoudy P, Kamler M, et al. Transcatheter aortic valve implantation in patients with very high risk for conventional aortic valve replacement. Ann Thorac Surg. 2009;88(5):1468-1474.

[19] Rosenhek R, Iung B, Tornos P, Antunes MJ, Prendergast BD, Otto CM, et al. ESC Working Group on Valvular Heart Disease Position Paper: assessing the risk of interventions in patients with valvular heart disease. Eur Heart J. 2012;33(7):822-828.

[20] Bustamante J, Gómez-Martínez ML, Bustamante E, Tamayo E. Occult chronic kidney disease in the ederly with coronary heart disease. Med Clin (Barc). 2009;133(13):524.

[21] Herreros JM. Cardiac surgery in elderly patients. Rev Esp Cardiol. 2002;55(11): 1114-1116.

[22] Lindroos M, Kupari M, Heikkilä J, Tilvis R. Prevalence of aortic valve abnormalities in the elderly: an echocardiographic study of a random population sample. J Am Coll Cardiol. 1993;21(5):1220-1225.

[23] Rodríguez R, Torrents A, García P, Ribera A, Permanyer G, Moradi M, et al. Cardiac surgery in elderly patients. Rev Esp Cardiol. 2002;55(11):1159-1168.

[24] Moat NE, Ludman P, de Belder MA, Bridgewater B, Cunningham AD, Young CP, et al. Long-term outcomes after transcatheter aortic valve implantation in high-risk patients with severe aortic stenosis: the U.K. TAVI (United Kingdom Transcatheter Aortic Valve Implantation) Registry. J Am Coll Cardiol. 2011;58(20):2130-2138.

[25] Likosky DS, Sorensen MJ, Dacey LJ, Baribeau YR, Leavitt BJ, DiScipio AW, et al. Long-term survival of the very elderly undergoing aortic valve surgery. Circulation. 2009;120(11 Suppl):S127-133.

[26] Yamane K, Hirose H, Youdelman BA, Bogar LJ, Diehl JT. Conventional aortic valve replacement for elderly patients in the current era. Circ J. 2011;75(11):2692-2698. 
[27] Brown JM, O'Brien SM, Wu C, Sikora JA, Griffith BP, Gammie JS. Isolated aortic valve replacement in North America comprising 108,687 patients in 10 years: changes in risks, valve types, and outcomes in the Society of Thoracic Surgeons National Database. J Thorac Cardiovasc Surg. 2009;137(1):82-90.

[28] Huber CH, Goeber V, Berdat P, Carrel T, Eckstein F. Benefits of cardiac surgery in octogenarians a postoperative quality of life assessment. Eur J Cardiothorac Surg. 2007;31(6):1099-1105.

[29] Kolh P, Lahaye L, Gerard P, Limet R. Aortic valve replacement in the octogenarians: perioperative outcome and clinical follow-up. Eur J Cardiothorac Surg. 1999;16(1): 68-73.

[30] Maillet JM, Somme D, Hennel E, Lessana A, Saint-Jean O, Brodaty D. Frailty after aortic valve replacement (AVR) in octogenarians. Arch Gerontol Geriatr. 2009;48(3): 391-396.

[31] Sundt TM, Bailey MS, Moon MR, Mendeloff EN, Huddleston CB, Pasque MK, et al. Quality of life after aortic valve replacement at the age of $>80$ years. Circulation. 2000;102(19 Suppl 3):III70-74.

[32] Dogan S, Dzemali O, Wimmer-Greinecker G, Derra P, Doss M, Khan MF, et al. Minimally invasive versus conventional aortic valve replacement: a prospective randomized trial. J Heart Valve Dis. 2003;12(1):76-80.

[33] Martens S, Sadowski J, Eckstein FS, Bartus K, Kapelak B, Sievers HH, et al. Clinical experience with the ATS $3 \mathrm{f}$ Enable ${ }^{\circledR}$ Sutureless Bioprosthesis. Eur J Cardiothorac Surg. 2011;40(3):749-755.

[34] Smith CR, Leon MB, Mack MJ, Miller DC, Moses JW, Svensson LG, et al. Transcatheter versus surgical aortic-valve replacement in high-risk patients. $\mathrm{N}$ Engl J Med. 2011;364(23):2187-2198.

[35] Harken, D.E., Soroff, H.S., Taylor, W.H. Aortic valve replacement, in Merendino KA (ed): Prosthetic Valves for Cardiac Surgery. Springfield, IL, Thomas; 1961, p 508-526

[36] Starr A, Edwards ML. Mitral replacement: clinical experience with a ball-valve prosthesis. Ann Surg. 1961; 154:726-740.

[37] Di Eusanio M, Fortuna D, Cristell D, Pugliese P, Nicolini F, Pacini D, et al. Contemporary outcomes of conventional aortic valve replacement in 638 octogenarians: insights from an Italian Regional Cardiac Surgery Registry (RERIC). Eur J Cardiothorac Surg. 2012;41(6):1247-1252.

[38] Rahimtoola SH. Choice of prosthetic heart valve in adults an update. J Am Coll Cardiol. 2010;55(22):2413-2426.

[39] Asimakopoulos G, Edwards MB, Taylor KM. Aortic valve replacement in patients 80 years of age and older: survival and cause of death based on 1100 cases: collective results from the UK Heart Valve Registry. Circulation. 1997;96(10):3403-3408. 
[40] Wu Y, Jin R, Gao G, Grunkemeier GL, Starr A. Cost-effectiveness of aortic valve replacement in the elderly: an introductory study. J Thorac Cardiovasc Surg. 2007;133(3):608-613.

[41] Cohn LH, Adams DH, Couper GS, Bichell DP, Rosborough DM, Sears SP, Aranki SF. Minimally invasive cardiac valve surgery improves patient satisfaction while reducing costs of cardiac valve replacement and repair. Ann Surg. 1997;226(4):421-426.

[42] Navia JL, Cosgrove DM 3rd. Minimally invasive mitral valve operations. Ann Thorac Surg. 1996;62(5):1542-1544

[43] Byrne JG, Karavas AN, Adams DH, Aklog L, Aranki SF, Couper GS, Rizzo RJ, Cohn $\mathrm{LH}$, et al. Partial upper re-sternotomy for aortic valve replacement or re-replacement after previous cardiac surgery. Eur J Cardiothorac Surg. 2000;18(3):282-286.

[44] Stamou SC, Kapetanakis EI, Lowery R, Jablonski KA, Frankel TL, Corso PJ. Allogeneic blood transfusion requirements after minimally invasive versus conventional aortic valve replacement: a risk-adjusted analysis. Ann Thorac Surg. 2003;76(4): 1101-1106.

[45] Corbi P, Rahmati M, Donal E, Lanquetot H, Jayle C, Menu P, et al. Prospective comparison of minimally invasive and standard techniques for aortic valve replacement: initial experience in the first hundred patients. J Card Surg. 2003;18(2):133-139.

[46] Detter C, Deuse T, Boehm DH, Reichenspurner H, Reichart B. Midterm results and quality of life after minimally invasive vs. conventional aortic valve replacement. Thorac Cardiovasc Surg. 2002;50(6):337-341.

[47] Doll N, Borger MA, Hain J, Bucerius J, Walther T, Gummert JF, et al. Minimal access aortic valve replacement: effects on morbidity and resource utilization. Ann Thorac Surg. 2002;74(4):S1318-1322.

[48] Farhat F, Lu Z, Lefevre M, Montagna P, Mikaeloff P, Jegaden O. Prospective comparison between total sternotomy and ministernotomy for aortic valve replacement. J Card Surg. 2003;18(5):396-401.

[49] Burfeind WR, Glower DD, Davis RD, Landolfo KP, Lowe JE, Wolfe WG. Mitral surgery after prior cardiac operation: port-access versus sternotomy or thoracotomy. Ann Thorac Surg. 2002;74(4):S1323-1325.

[50] Sharony R, Grossi EA, Saunders PC, Schwartz CF, Ribakove GH, Culliford AT, et al. Minimally invasive aortic valve surgery in the elderly: a case control study. Circulation. 2003;108 Suppl 1:II43-47.

[51] Galloway AC, Shemin RJ, Glower DD, Boyer JH Jr, Groh MA, Kuntz RE, et al. First report of the Port Access International Registry. Ann Thorac Surg. 1999;67(1):51-56.

[52] Falk V, Walther T, Autschbach R, Diegeler A, Battellini R, Mohr FW. Robot-assisted minimally invasive solo mitral valve operation. J Thorac Cardiovasc Surg. 1998;115(2):470-471. 
[53] Carpentier A, Loulmet D, Aupècle B, Kieffer JP, Tournay D, Guibourt P, et al. Computer assisted open heart surgery. First case operated on with success. C R Acad Sci III. 1998;321(5):437-442.

[54] Bustamante J, Cánovas S, Fernández AL, Minimally Invasive Aortic Valve Surgery New Solutions to Old Problems In Hirota M (Ed) Aortic Stenosis - Etiology, Pathophysiology and Treatment. Rijeka: InTech; 2012. p 91-114.

[55] Bonacchi M, Prifti E, Giunti G, Frati G, Sani G. Does ministernotomy improve postoperative outcome in aortic valve operation? A prospective randomized study. Ann Thorac Surg. 2002;73(2):460-465.

[56] Moustafa MA, Abdelsamad AA, Zakaria G, Omarah MM. Minimal vs median sternotomy for aortic valve replacement. Asian Cardiovasc Thorac Ann. 2007;15(6): 472-475.

[57] Yap CH, Sposato L, Akowuah E, Theodore S, Dinh DT, Shardey GC, et al. Contemporary results show repeat coronary artery bypass grafting remains a risk factor for operative mortality. Ann Thorac Surg. 2009;87(5):1386-1391.

[58] Yau TM, Borger MA, Weisel RD, Ivanov J. The changing pattern of reoperative coronary surgery: trends in 1230 consecutive reoperations. J Thorac Cardiovasc Surg. 2000;120(1):156-163.

[59] Cosgrove DM 3rd, Sabik JF, Navia JL. Minimally invasive valve operations. Ann Thorac Surg. 1998;65(6):1535-1538.

[60] Tam RK, Almeida AA. Minimally invasive aortic valve replacement via partial sternotomy. Ann Thorac Surg. 1998;65(1):275-276.

[61] Mächler HE, Bergmann P, Anelli-Monti M, Dacar D, Rehak P, Knez I, et al. Minimally invasive versus conventional aortic valve operations: a prospective study in 120 patients. Ann Thorac Surg. 1999;67(4):1001-1005.

[62] Candaele S, Herijgers P, Demeyere R, Flameng W, Evers G. Chest pain after partial upper versus complete sternotomy for aortic valve surgery. Acta Cardiol. 2003;58(1): 17-21.

[63] Liu J, Sidiropoulos A, Konertz W. Minimally invasive aortic valve replacement (AVR) compared to standard AVR. Eur J Cardiothorac Surg. 1999;16 Suppl 2:S80-83.

[64] Grossi EA, Galloway AC, Ribakove GH, Zakow PK, Derivaux CC, Baumann FG,et al. Impact of minimally invasive valvular heart surgery: a case control study. Ann Thorac Surg. 2001;71(3):807-810.

[65] Lee JW, Lee SK, Choo SJ, Song H, Song MG. Routine minimally invasive aortic valve procedures. Cardiovasc Surg. 2000;8(6):484-490.

[66] Tabata M, Umakanthan R, Cohn LH, Bolman RM 3rd, Shekar PS, Chen FY, et al. Early and late outcomes of 1000 minimally invasive aortic valve operations. Eur J Cardiothorac Surg. 2008;33(4):537-541. 
[67] de Vaumas C, Philip I, Daccache G, Depoix JP, Lecharny JB, Enguerand D, et al. Comparison of minithoracotomy and conventional sternotomy approaches for valve surgery. J Cardiothorac Vasc Anesth. 2003;17(3):325-328.

[68] Cribier A, Eltchaninoff H, Bash A, Borenstein N, Tron C, Bauer F, et al. Percutaneous transcatheter implantation of an aortic valve prosthesis for calcific aortic stenosis: first human case description. Circulation. 2002;106(24):3006-3008.

[69] Charlson E, Legedza AT, Hamel MB. Decision-making and outcomes in severe symptomatic aortic stenosis. J Heart Valve Dis. 2006;15(3):312-321.

[70] Pellikka PA, Sarano ME, Nishimura RA, Malouf JF, Bailey KR, Scott CG, et al. Outcome of 622 adults with asymptomatic, hemodynamically significant aortic stenosis during prolonged follow-up. Circulation. 2005;111(24):3290-3295.

[71] Holmes DR Jr, Mack MJ. Transcatheter valve therapy a professional society overview from the American college of cardiology foundation and the society of thoracic surgeons. J Am Coll Cardiol. 2011;58(4):445-455.

[72] Cox JL, Ad N, Myers K, Gharib M, Quijano RC. Tubular heart valves: a new tissue prosthesis design- preclinical evaluation of the $3 \mathrm{~F}$ aortic bioprosthesis. J Thorac Cardiovasc Surg. 2005;130(2):520-527.

[73] Pillai R, Ratnatunga C, Soon JL, Kattach H, Khalil A, Jin XY. 3f prosthesis aortic cusp replacement: implantation technique and early results. Asian Cardiovasc Thorac Ann. 2010;18(1):13-16.

[74] Wendt D, Thielmann M, Buck T, Jánosi RA, Bossert T, Pizanis N, et al. First clinical experience and 1-year follow-up with the sutureless 3F-Enable aortic valve prosthesis. Eur J Cardiothorac Surg. 2008;33(4):542-547.

[75] Flameng W, Herregods MC, Hermans H, Van der Mieren G, Vercalsteren M, Poortmans $G$, et al. Effect of sutureless implantation of the Perceval $S$ aortic valve bioprosthesis on intraoperative and early postoperative outcomes. J Thorac Cardiovasc Surg. 2011;142(6):1453-1457.

[76] Shrestha M, Folliguet T, Meuris B, Dibie A, Bara C, Herregods MC, et al. Sutureless Perceval S aortic valve replacement: a multicenter, prospective pilot trial. J Heart Valve Dis. 2009;18(6):698-702.

[77] Aymard T, Kadner A, Walpoth N, Göber V, Englberger L, Stalder M, et al. Clinical experience with the second-generation $3 f$ Enable sutureless aortic valve prosthesis. J Thorac Cardiovasc Surg. 2010;140(2):313-316. 